\title{
Peran Pendidikan Kewarganegaraan di Era Globalisasi Dalam Pembentukan Karakter Siswa
}

\author{
Siti Humaeroh, Dinie Anggraeni Dewi ${ }^{2}$ \\ ${ }^{1,2}$ Program Studi Pendidikan Guru Sekolah Dasar, Fakultas Ilmu Pendidikan, Universitas Pendidikan Indonesia \\ Jl. Pendidikan No.15, Cibiru, Wetan, Cileunyi, Bandung, Indonesia \\ 07siti.humaeroh@upi.edu
}

\begin{abstract}
Science and technology are experiencing rapid developments marking the entry of globalization in a country. Globalization has had a major impact, both positive and negative. This globalization affects the lifestyle of the westernized society and reduces the values and nationalism of the Indonesian nation. Education is one of the most effective ways to build good character for the younger generation. This research was conducted using qualitative data collection. It is found that character education has a function as a vehicle for development, improvement, and filter. In addition, character education has other functions, namely developing potential, habits, and behavior, fostering leadership and responsibility, developing abilities and the school environment. Citizenship education has functions including building participatory skills that make Indonesian citizens active, critical, intelligent, and democratic, as well as building a civilized democratic culture. Based on the research, the suggestion that can be given is that there is a need for the involvement of all parties in paying attention and participating in building the character of students as the future generation of the Indonesian nation.
\end{abstract}

Keywords: Citizenship education, character education, globalization, students

\begin{abstract}
Abstrak
Ilmu pengetahuan dan teknologi mengalami perkembangan yang cepat menandai masuknya globalisasi disuatu negara. Globalisasi mempunyai pengaruh besar baik positif maupun negatif. Globalisasi ini memengaruhi gaya hidup masyarakat yang kebarat-baratan dan mengurangi nilai-nilai dan nasionalisme bangsa Indonesia. Pendidikan menjadi salah satu jalan yang efektif dalam pembentukan karakter yang baik untuk generasi muda. Penelitian ini dilakukan menggunakan pengumpulan data secara kualitatif. Didapat bahwa pendidikan karakter memiliki fungsi sebagai wahana pengembangan, perbaikan, dan penyaring. Selain itu, pendidikan karakter memiliki fungsi lainnya yaitu mengembangkan potensi, kebiasaan, dan perilaku, menumbuhkan jiwa kepemimpinan dan tanggung jawab, mengembangkan kemampuan serta lingkungan sekolah. Pendidikan kewarganegaraan memiliki fungsi diantaranya membangun keterampilan partisipatif yang menjadikan warga negara Indonesia yang aktif, kritis, cerdas, dan demokratis, serta membangun kebudayaan demokrasi yang berkeadaban. Berdasarkan penelitian saran yang dapat diberikan adalah perlu adanya keterlibatan semua pihak dalam memperhatikan dan ikut serta dalam membangun karakter siswa sebagai generasi penerus masa depan bangsa Indonesia.
\end{abstract}

Kata kunci: Pendidikan kewarganegaraan, Pendidikan karakter, globalisasi, siswa

Copyright (C) 2021 Siti Humaeroh, Dinie Anggraeni Dewi

$\triangle$ Corresponding author: Siti Humaeroh

Email Address: 07siti.humaeroh@upi.edu (Jl. Pendidikan No.15, Cibiru, Wetan, Cileunyi, Bandung)

Received 22 March 2020, Accepted 24 April 2020, Published 30 April 2021

\section{PENDAHULUAN}

Perkembangan seperti ilmu pengetahuan dan teknologi yang pesat menandai masuknya globalisasi pada suatu negara. Kata globalisasi sudah digunakan pada akhir abad ke-19 yang tentunya sudah tidak asing lagi untuk didengar, bahkan globalisasi sudah meluas hingga ke seluruh dunia. Masuknya globalisasi ini tidak bisa dihindari karena ketika kita menghidari perubahan dan perkembangan itu, kita akan menjadi negara yang tertinggal. Selain itu, globalisasi juga dijadikan sebagai jalan untuk memperkenalkan identitas dan membanggakan suatu negara karena globalisasi ini sudah mendunia. Globalisasi diibaratkan sebagai dua mata pisau yang sangat tajam dan mesti 
Peran Pendidikan Kewarganegaraan di Era Globalisasi Dalam Pembentukan Karakter Siswa, Siti Humaeroh, Dinie

diwaspadai. Menurut Anwar Rubei, M. (2015) mengatakan walaupun sudah bebas dalam membangun hubungan antar individu bahkan seluruh dunia, pasti tetap memiliki perbedaan yang unik dan hanya karakter tersebutlah yang dapat membedakan antara satu individu dengan individu yang lain.

Globalisasi sendiri mempunyai pengaruh besar baik positif maupun negatif bagi suatu negara. Pengaruh positif yang dirasakan dari globalisasi dalam penataan nilai dan sikap yaitu, adanya perubahan nilai-nilai dan sikap masyarakat yang menjadi lebih logis dan masuk akal. Berbagai manfaat yang diberikan globalisasi memberikan kemudahan yang bisa dirasakan saat ini, namun berbagai kemudahan inilah yang seringkali malah memanjakan. Selain itu, globalisasi memengaruhi gaya hidup yang kebarat-baratan dan mengurangi nilai-nilai dan nasionalisme bangsa, bahkan dampak dari globalisasi memengaruhi aspek pendidikan yang berpengaruh pada bagaimana cara siswa berpikir, bersikap, dan bagaimana masyarakat bertindak (Sakman, \& Bakhtiar., 2019). Dampak dari globalisasi tersebut akan menghilangkan nilai-nilai jati diri bangsa maupun identitas nasional bangsa Indonesia, dan eksistensi Pancasila pun lambat laun akan mengalami kemunduran seiring dengan kemajuan dan perkembangan zaman, pengetahuan, serta teknologi saat ini. Sugiana Fitrayadi, D. (2016) mengatakan jika nilai-nilai luhur Pancasila sudah mulai dilupakan oleh masyarakat Indonesia.

Bahkan era reformasi juga memperlihatkan tentang banyaknya generasi muda saat ini yang tidak memahami apa itu filsafat bangsa dan negaranya. Selain itu, tidak sedikit generasi muda justru tidak mengingat butir-butir Pancasila. Hal tersebut menimbulkan pertanyaan tentang "bagaimana mungkin generasi muda saat ini dapat mengamalkan nilai-nilai Pancasila bila tidak bisa menghafal" (Charlaes Bego, K., 2016). Adanya penurunan kualitas moral yang mengakibatkan perilaku-perilaku menyimpang menjadi salah satu dampak negatif dari globalisasi. Fakta bahwa banyaknya persoalan tentang karakter sudah tidak bisa dipungkiri. Maka dari itu, diperlukan pembentukan karakter sebagai upaya yang dilakukan untuk memperbaiki kualitas moral bangsa. Karakter sendiri terbentuk dari suatu proses dan memberikan pengaruh terhadap keluarga, lingkungan, masyarakat, bangsa, dan masa depan seseorang. Karakter dapat mengendalikan suatu bangsa. Hal ini dapat dilihat apabila warga dalam suatu negara mempunyai karakter individu yang baik, maka kemungkinan besar masa depan dari negara itu juga akan baik. Kesejahteraan suatu negara juga dipengaruhi dari karakter warga negaranya.

Pendidikan sebagai salah satu jalan yang efektif dalam pembentukan karakter yang baik untuk generasi muda (siswa). Hal demikian seperti dalam Undang-Undang Sistem Pendidikan Nasional (Sisdiknas) No. 20 Tahun 2003 pasal 1 ayat 1. Dalam undang-undang tersebut pengertian pendidikan sangat memprioritaskan pada pembentukan karakter peserta didik. Pembangunan karakter dijadikan jalan utama dalam pembangunan nasional yang diharapkan dapat memberikan dampak positif bagi pengembangan karakter. Hal tersebut dapat dilihat dalam misi pembangunan nasional yang meletakkan pendidikan karakter pada misi yang utama untuk merealisasikan visi pembangunan nasional. Dianti, P. (2014) mengutarakan bahwa Pendidikan karakter ini harus diawali dengan menanamkan pengetahuan atau kecerdasan tentang hal-hal baik yang patut dilakukan serta hal-hal 
yang tidak patut dilakukan dan pengetahuan tersebut dapat diimplementasikan pada bentuk sikap setiap individu.

Adanya pendidikan karakter inilah seseorang dapat menjadi cerdas dalam berfikir maupun dalam mengontrol emosi dalam dirinya. Cerdas dalam pengendalian emosi ini dapat dijadikan sebagai bekal yang penting untuk mempersiapkan peserta didik bertahan di dalam kehidupannya. Dengan kecerdasan emosional, seseorang dapat melawan berbagai macam rintangan, bahkan rintangan untuk meraih kesuksesan dalam hal akademis (Meilan Siadari, R., 2018). Selain itu, tugas dan tanggung jawab negara ialah mewarganegarakan orang yang hidup dalam negara tersebut. Hal tersebut sesuai dengan penduduk negara yang baik (smart and good citizenship) agar dapat diimplementasikan diberbagai negara lain. Seperti yang dijabarkan oleh Tuhuteru, L. (2017) bahwa Pendidikan Kewarganegaraan yaitu, pelajaran yang gunanya untuk memusatkan perhatian pada bagaimana cara penjadian diri yang memiliki banyak perbedaan serta keberagaman seperti dari agama, sosial budaya, bahasa, usia, dan suku bangsa untuk membentuk masyarakat yang cerdas, terampil, kreatif dan memiliki karakter yang pantas dengan nilai-nilai Pancasila dan UUD 1945.

Akhir dari tujuan Pendidikan Kewarganegaraan bukan hanya bagaimana masyarakat bisa tanggap, kritisasi, dan kreatifitas sosial tetapi tujuan akhirnya adalah untuk menanamkan moral yang diharapkan dapat membentuk moral mulia masyarakat (Andrian, A., 2017). Pendidikan Kewarganegaraan bukan hanya mengahafal, tetapi diimplementasikan pada kehidupan sehari-hari siswa yang diterapkan pada perbuatan yang berdasar pada nilai-nilai dalam Pancasila. Cara mengajar pendidikan kewarganegaraan tentu memiliki perbedaan dengan cara mengajar pendidikan lainnya. Menurut Agassy Sihombing, R., \& Suhendro Lukitoyo, P. (2021) Hal ini karena cara mengajar pendidikan kewarganegaraan cenderung sukar untuk mendapat ketepatan daripada cara mengajar ilmu eksak lainnya seperti IPA.

Pkn sendiri sebagai Pendidikan Politik dan Pendidikan umum yang memberi jalan keluar untuk kerja sama antara sekolah dengan keluarga, antara guru dengan orang tua guna membuat pendidikan yang bermakna serta mempunyai tujuan untuk memajukan dan mendidik warga negara agar mempunyai karakter sebagai seorang warga negara (Rohayani, I., Djahiri, A. K., \& Sapriya., 2010). Hal ini menunjukkan pentingnya Pendidikan Kewarganegaraan sebagai upaya pembentukan karakter. Pendidikan kewarganegaraan sendiri memuat pembelajaran tentang nilai-nilai karakter dapat membentuk karakter siswanya terutama dalam menyesuaikan norma dimasyarakat dalam era globalisasi.

\section{METODE}

Teknik dan metode penelitian yang dipergunakan adalah dengan pengumpulan data secara kualitatif atau pendekatan deskriptif. Peneliti memfokuskan pada sumber teori yang kemudian dianalisis dan ditafsirkan hingga membuat kesimpulan. Metode penelitian ini didasari oleh pendapat dan teori para ahli serta hasil penelitian sebelumnya yang didapat dari hasil studi kepustakaan. 
Peran Pendidikan Kewarganegaraan di Era Globalisasi Dalam Pembentukan Karakter Siswa, Siti Humaeroh, Dinie Anggraeni Dewi

Referensi yang digunakan berhubungan dengan penelitian serta permasalahan yang membahas mengenai pendidikan kewarganegaan dalam pembentukan karakter.

\section{HASIL DAN DISKUSI}

Karakter ini sering disamakan dengan budi pekerti, bahkan ada yang mendefinisikannya sebagai system keyakinan serta kebiasaan. Jadi dapat disimpulkan bahwa karakter yaitu, moral atau akhlak yang terdapat di dalam pikiran atau dapat dikatakan karakter tersebut merupakan suatu yang ditanamkan oleh lingkungan keluarga yang menjadi kebiasaan. Setiap siswa mempunyai karakter yang berbeda-beda. Hal ini dikarenakan setiap keluarga menanamkan karakter yang berbeda sehingga menjadi suatu kebiasaan. Nilai karakter menjadi hal yang penting dalam Pendidikan Kewarganegaraan karena harus disesuaikan dengan tujuan dari pembelajaran Pendidikan Kewarganegaraan. Menurut Kemendiknas dalam (Karim, N., 2010) mengatakan Pendidikan karakter memiliki fungsi antara lain:

1. Sebagai wahana pengembangan potensi siswa untuk bertingkah laku baik bagi siswa yang sudah mempunyai sikap dan perilaku menggambarkan.

2. Sebagai wahana perbaikan yang dapat memperkuat pendidikan nasional untuk bisa bertanggung jawab terlebih dalam mengembangkan potensi siswa yang lebih bermartabat.

3. Sebagai wahana penyaring yang dapat menyaring budaya bangsa negara sendiri dan bangsa lain yang tidk sesuai dengan nilai-nilai karakter (Karim, N., 2010).

Sedangkan tujuan pendidikan karakter menurut Kemendiknas dalam (Karim, N., 2010) sebagai berikut:

1. Untuk mengembangkan potensi Nurani atau afektif siswa sebagai manusia serta warganegara yang mempunyai nilai karakter.

2. Untuk mengembangkan perilaku dan kebiasaan yang baik dan sesuai dengan nilai-nilai universal dan tradisi budaya bangsa religius.

3. Untuk menumbuhkan jiwa kepemimpinan dan tanggung jawab sebagai penerus bangsa.

4. Untuk mengembangkan kemampuan siswa menjadi manusia yang mandiri, kreatif, dan berwawasan kebangsaan.

5. Untuk mengembangkan lingkungan sekolah sebagai lingkungan belajar yang aman, jujur, penuh kreativitas dan persahabatan, serta adanya rasa kebangsaan yang tinggi dan penuh kekuatan (Karim, N., 2010).

Hermanto mengemukakan dalam (Widiatmaka, P. 2016) "Pendidikan Kewarganegaraan mempunyai peran yang sangat penting terutama untuk menanamkan dan mengembangkan pola pikir, sikap, dan perilaku rukun, damai, serta toleransi dan tidak melupakan kebhinekaan yang menjadi given-nya bangsa Indonesia”. Dapat dikatakan bahwa pelajaran yang mampu mencapai tujuan nasional adalah Pendidikan Kewarganegaraan saja. Namun, hal ini terjadi apabila Pendidikan Kewarganegaraan sendiri mampu menjalankan perannya terutama di era globalisasi. Maka dari itu, 
untuk mencapai tujuan nasional, pembelajaran Pendidikan Kewarganegaraan harus diimplementasikan dalam semua jenjang pendidikan dari sekolah dasar, menengah, maupun perguruan tinggi.

Pendidikan Kewarganegaraan mempunyai kedudukan dan peran yang penting dalam pembangunan bangsa dan karakter, sehingga besar tanggung jawab yang dimiliki dalam mennggapai tujuan nasional untuk mencerdaskan kehidupan bangsa Indonesia. Pendidikan Kewarganegaraan menjadi hal yang dasar yang dapat membawa siswanya memahami berbagai aturan, nilai-nilai, sistem, peranan dan yang berhubungan dengan kemasyarakatan serta kenegaraan. Sebenarnya peran dalam pembentukan karakter tidak hanya tugas dari pendidikan Pendidikan Kewarganegaraan saja, tetapi mengingat Pendidikan Kewarganegaraan merupakan pendidikan moral bangsa sehingga mempunyai tanggung jawab yang besar. Adapun tujuan dari Pendididkan Kewarganegaraan yaitu untuk mencetak generasi muda yang mempunyai rasa tanggung jawab atas keselamatan dan kejayaan tanah airnya. Rasa tanggung jawab yang dimiliki generasi penerus ini akan tercermin dalam partisipasi aktifnya dalam pembangunan seperti, menyaring dan memilah pengaruh-pengaruh globalisasi yang masuk, dapat mengambil pembelajaran dan sisi positif serta dapat menyaring setiap hal yang memang kurang sesuai dengan nilai dan moral bangsa. Jadi, adanya Pendidikan Kewarganegaraan untuk membentuk generasi penerus yang mempunyai ilmu pengetahuan, mengembangkan keahliannya, serta mengembangan karakternya. Walaupun pengembangan ini dapat dipelajari tanpa harus melalui Pendidikan Kewarganegaraan, lebih baik jika pendidikan ini dimanfaatkan guna mengembangkan diri seluas-luasnya karena jika memiliki rasa kebangsaan yang tinggi, maka tidak akan mudah terpengaruh terhadap janji-janji kejayaan yang hanya sementara, budaya-budaya asing yang datang selain dari Indonesia, dan dapat lebih mengahargai serta mempunyai rasa kebanggaan terhadap bangsa, budaya, dan nilai-nilai yang terdapat di Indonesia.

Pembelajaran Pendidikan Kewarganegaraan yang diterapkan melalui perencanaan yang baik, pelaksanaan pembelajaran berdasarkan tujuan pendidikan, dan adanya evaluasi sebagai pemantauan pembelajaran, maka tujuan dari Pendidikan Kewarganegaraan dapat dicapai dengan baik. Selain itu, dapat membentuk peserta didik sebagai individu yang mempunyai kesadaran akan hak serta kewajibannya yang merupakan bagian dari NKRI. Sehingga, semakin tinggi tingkat kualitas penerapan pembelajaran Pendidikan Kewarganegaraan, maka semakin baik pula kesadaran siswa dalam memegang peranan sebagai penerus bangsa di era globalisasi.

Sistem pendidikan nasional sendiri menurut Baehaqi Arif, D. (2011) memiliki fungsi untuk menumbuhkan keterampilan dan membangun karakter serta kebudayaan bangsa Indonesia menjadi lebih terhormat dalam mencerdaskan kehidupan bangsa dan memiliki tujuan memajukan kemampuan siswanya menjadi individu yang beriman dan bertakwa kepada Tuhan Yang Maha Esa, memiliki akhlak yang mulia, sehat, memiliki ilmu, cakap, kreatif, mandiri, dan menjadi masyarakat Indonesia yang demokratis.

\section{KESIMPULAN}


Peran Pendidikan Kewarganegaraan di Era Globalisasi Dalam Pembentukan Karakter Siswa, Siti Humaeroh, Dinie

Perlunya pembentukan karakter di era globalisasi yang pengaruhnya tidak bisa dihindari dan dapat masuk kapan saja ke dalam bangsa ini. Karakter dapat mengendalikan suatu bangsa. Hal ini dapat dilihat apabila warga dalam suatu negara mempunyai karakter individu yang baik, maka kemungkinan besar masa depan dari negara itu juga akan baik. Pembangunan karakter dijadikan jalan utama dalam pembangunan nasional yang diharapkan dapat memberikan dampak positif bagi pengembangan karakter. Maka dari itu perlu peran dari Pendidikan Kewarganegaraan sebagai upaya dalam pembentukan karakter siswa.

Pendidikan Kewarganegaraan sebagai suatu usaha dalam meningkatkan kualitas warga negara melalui pendidikan. Peranan dari pendidikan sangatlah penting dalam membangun karakter siswa. Pendidikan Kewarganegaraan menjadi penyangga dalam membangun karakter yang artinya Pendidikan Kewarganegaraan membimbing peserta didik untuk menjadi warga negara yang baik terlebih sebagai generasi penerus yang akan menghadapi perkembangan dan perubahan dunia di era globalisasi. Melalui Pendidikan Kewarganegaraan diharapkan mampu membangun sikap yang setia kepada tanah air dan sanggup menyumbangkan setiap potensi secara tulus dan ikhlas untuk kemajuan tanah air. Tanggung jawab yang dimiliki Pendidikan Kewarganegaraan dalam menggapai tujuan nasional dan mencerdaskan kehidupan bangsa dan karakter agar generasi penerus dapat memiliki pribadi yang bertanggung jawab, berbudi luhur, bermoral, serta menjadi warga yang baik. Sebagai pelajaran pendidikan moral, Pendidikan Kewarganegaraan adalah salah satu solusi untuk mengarahkan perkembangan karakter peserta didik yang berdasar Pancasila. Seharusnya, Pendidikan Kewarganegaraan setiap lembaga pendidikan dilakukan dengan cara terus menerus dan berkaitan dengan situasi sosial masa kini.

\section{UCAPAN TERIMA KASIH}

Terimakasih kepada Dosen Pembimbing Dinie Anggraeni Dewi, M.Pd. yang telah meluangkan waktunya untuk membimbing saya sehingga artikel ini dapat terlaksana dengan baik. Terimakasih pula kepada keluarga terutama kedua orang tua saya dan teman-teman yang selalu memberikan doa terbaik dan tidak kenal lelah mendengar keluh kesah saya dan selalu memberi dukungan selama ini.

\section{REFERENSI}

Agassy Sihombing, R., \& Suhendro Lukitoyo, P. (2021). Peranan Penting Pancasila Dan Pendidikan Kewarganegaraan Sebagai Pendidikan Karakter di Masa Pandemi Covid-19. Jurnal Pendidikan Kewarganegaraan Undiksha Vol. 9 No. 1.

Andrian, A. (2017). Pengembangan Karakter Siswa Melalui Pendidikan Kewarganegaraan Untirta Civic Education Journal, 2(1).

Anwar Rubei, M. (2015). Integrasi Pendidikan Karakter Dalam Pembelajaran Pkn Untuk 
Mengembangkan Kemandirian Siswa di Mts. Mathlaul Anwar Kota Pontianak. Sosial Horizon: Jurnal Pendidikan Sosial Vol. 2, No. 2,

Baehaqi Arif, D. (2011). Pendidikan Kewarganegaraan Untuk Pembangunan Karakter Bangsa (Prospek dan Tantangan di Tengah Masyarakat Yang Multikultural)1.

Charlaes Bego, K. (2016). Peran Guru Pendidikan Kewarganegaraan Dalam Membentuk Karakter Siswa dan Implikasinya Terhadap Ketahanan Siswa. Jisip: Jurnal Ilmu Sosial dan IlmuPolitik.

Dianti, P. (2014). Integrasi Pendidikan Karakter dalam pembelajaran Pendidikan Kewarganegaraan untuk mengembangkan karakter siswa. Jurnal Pendidikan Ilmu Sosial, 23(1).

Meilan Siadari, R. (2018). Pkn Sebagai Pendidikan Karakter Berbasis Nilai Untuk Anak Sekolah Dasar. Pendidikan Dasar Universitas Negeri Medan.

Rohayani, I., Djahiri, A. K., \& Sapriya. (2010). Pengaruh Proses Pembelajaran Pendidikan Kewarganegaraan dan Pendidikan Interventif Terhadap Karakter Warga Negara Muda (Studi Deskriptif AnalitisPada Siswa SMA Negeri 3 Bandung). Sekolah Pascasarjana Upi.

Sakman, \& Bakhtiar. (2019). Pendidikan Kewarganegaraan Dan Degradasi Moral di Era Globalisasi. Fakultas Ilmu Sosial, Univeritas Negeri Makassar,

Sugiana Fitrayadi, D. (2016). Peran Pendidikan Kewarganegaraan Dalam Mengembangkan Karakter Tanggungjawab Peserta Didik di Era Globalisasi di SMA Negeri 1 Baleendah. Untirta Civic Education Journal.

Tuhuteru, L. (2017). Peran Pendidikan Kewarganegaraan dalam Peningkatan Pembentukan Karakter Bangsa di Tengah Arus Globalisasi. Prosiding Konferensi Nasional Kewarganegaraan III.

Karim, N. (2010). Pendidikan karakter. Shautut Tarbiyah, 16(1), 69-89.

Kemendiknas, 2010, Seri pendidikan Karakter: Teori dan Aplikasinya, Jakarta: Kemendiknas RI.

Widiatmaka, P. (2016). Kendala Pendidikan Kewarganegaraan dalam membangun karakter peserta didik di dalam proses pembelajaran. Jurnal Civics, 13(2), 188-198. DOI: https://doi.org/10.21831/civics.v13i2.12743

Undang-Undang, R. I. No, 20 Tahun 2003 Pasal 1. 2003. Sistem Pendidikan Nasional. Diperoleh 5 Oktober 2014. 